\title{
Digestion of fibre polysaccharides of pea (Pisum sativum) hulls, carrot and cabbage by adult cockerels
}

\author{
BY M. LONGSTAFF AND J.M. MCNAB \\ AFRC Institute for Grassland and Animal Production, Poultry Department, \\ Roslin, Midlothian EH25 9PS
}

(Received 16 August 1988 - Accepted 3 May 1989)

\begin{abstract}
Characterization of the carbohydrates of pea (Pisum sativum) hulls, carrot and cabbage using both colorimetric and gas-liquid chromatographic techniques permitted a detailed investigation into the extent of digestion of differing types of fibre. These digestion studies were greatly aided by the development of a rapid bioassay employing starved adult cockerels. Total collection of undigested residues, uncontaminated by food spillage, could be made from trays placed under the cockerels. Chemical analysis showed that pea hulls consisted mainly of fibre with very little available carbohydrate present, whereas more than half of freeze-dried carrot and cabbage consisted of available carbohydrate (sucrose, glucose, fructose, starch) and consequently considerably less fibre was present. The fibre of carrot and cabbage was similarly composed of nearly equal amounts of neutral and acidic polysaccharides, whereas pea-hull fibre had four times as much neutral as acidic polysaccharides. The digestibility of total neutral polysaccharides from all three foodstuffs was extremely low. However, there appeared to be preferential digestion of polysaccharides composed of rhamnose, arabinose and galactose residues, all associated with pectic material, in contrast to the indigestibility of polysaccharides composed of fucose, xylose and glucose. Acidic polysaccharides were digested to a greater extent than neutral ones, and those of carrot and cabbage more so than pea hulls. The polysaccharides which were the most soluble were also the most digestible, but due to the arbitrariness of polysaccharide solubility, quantification of their total digestibility per se was considered not possible.
\end{abstract}

Fibre polysaccharides: Digestion: Cockerels

The increased use of methods for fibre analysis whereby the neutral sugar constituents from the hydrolysis of the fibre polysaccharides are converted to alditol acetate derivatives (Åman \& Nordkvist, 1983; Ben-Ghedalia \& Miron, 1984; Carre \& Leclercq, 1985; Graham et al. 1985; Longstaff \& McNab, 1986, 1987; Nordkvist \& Åman, 1986), which are measured by gas-liquid chromatography, has permitted a more informed discussion on the relationship between polysaccharide structure and its digestion. In this context, fibre represents the sum of the individual neutral sugars together with the uronic acids from pectic substances and acidic xylans. The uronic acids are usually determined separately by either colorimetric (Blumenkrantz \& Asboe-Hansen, 1973) or decarboxylation methods (Bylund \& Donetzhuber, 1968; Theander \& Áman, 1979). These more definitive methods invariably produce lower estimations of fibre compared with the older gravimetric procedures of crude fibre (Williams \& Olmsted, 1925), neutral-detergent fibre (NDF) and acid-detergent fibre (ADF) (Goering \& Van Soest, 1970; Asp \& Johansson, 1981). Discrepancies between the amounts of fibre derived by the newer and older methods are believed to be caused, in part, by losses of the more labile sugars during hydrolysis and incomplete hydrolysis of the more acid-resistant polysaccharide linkages using the newer methods, while the major source of error in the gravimetric methods is the inclusion of nonpolysaccharides as fibre. It would seem that many more studies will be required to validate these newer methods, particularly with fibre digestion in simple-stomached animals. 
The recent clinical interest in fibre digestion in man (Eastwood \& Robertson, 1978; Stephen \& Cummings, 1980; Eastwood, 1985) has stimulated numerous studies with simple-stomached animals (Gohl \& Gohl, 1977; Low \& Rainbird, 1984; Carre \& Leclercq, 1985; Johnson \& Gee, 1986; Nyman et al. 1986) that have implicated fibre in a number of digestive and physiological gut functions. Most of these studies have concentrated on the complex physiological roles of polysaccharides such as their ability to $(a)$ delay gastric emptying, $(b)$ function as diluents such that absorption is delayed, $(c)$ promote fermentation and $(d)$ act as chelators or exchange resins. Viscous polysaccharides, both ionic (pectins) and non-ionic (guar gum) are believed to affect lipid metabolism in several ways: by lowering blood cholesterol (Mathe et al. 1977; Cerda et al. 1985) and by promoting excretion of bile salts (Meittinen \& Tarpila, 1977; Robertson et al. 1980), or through the production of fermentation products such as propionic acid, the sodium salt of which has been shown to lower blood and liver cholesterol (Chen et al. 1984). Viscous polysaccharides have also been shown to reduce blood glucose either by slowing gastric emptying (Tsai \& Peng, 1981) or by interfering with absorption (Jenkins et al. 1977).

Interest in the extent to which fibre is fermented in simple stomached animals by caecal or colonic bacteria has increased in recent years. Evidence of fermentation, however, has been largely by implication, deduced from the difference between the quantity of fibre found in the diet and that in the excreta rather than from direct measurement of volatile fatty acids. The few studies on fibre digestion by chickens has given estimates of implied fermentation of about 15-33\% with graminaceous fibre (Bolton, 1954, 1955; Longstaff \& McNab, 1986), 20-30\% digestion of pea (Pisum sativum) fibre (Longstaff \& McNab, 1987) and none at all of the insoluble fibre in lupin (Lupinus luteus) seeds (Carre \& Leclercq, 1985). Pigs, on the other hand, have been reported to derive much more energy from fibre than chickens. Graham et al. (1985) reported over $50 \%$ degradation of both pea and barley fibre by pigs; Millard \& Chesson (1984) reported 46-50\% degradation of uronic acids, and $10-24 \%$ of cellulose anterior to the terminal ileum in pigs fed on swedes (Brassica napus); and other studies have reported $50 \%$ digestion of sugar-beet fibre and $20 \%$ digestion of wheat-bran fibre (Graham et al. 1986). Stanogias \& Pearce (1985) reported 2.6-9.3\% cellulose digestion and between 1 and $99.9 \%$ digestion of hemicelluloses ingested by the pig. Wheat-bran-fibre digestion in the rat was reported to be zero (Mathe et al. 1977), while more recent studies by Bach Knudsen et al. (1985) showed fibre from barley, barley + aleurone, and barley + husk to be digested by the rat to the extent of 61,56 and $38 \%$ respectively; moreover caecectomy lowered this digestion to 38,19 and $16 \%$ respectively. Nyman et al. (1986), who believe that rats can be used as models in human digestion studies, reported about $40 \%$ digestion of wheat bran fibre by rats and $34 \%$ digestion in humans, and between 75 and $90 \%$ digestion of fibre from legumes and fruit in both species.

In the present study when referring to digestibility of fibre, the word is intended to mean its overall disappearance from the gut. Reasons for finding a lower amount of fibre sugar residues in the excreta compared with that in the foodstuff may be due to several factors. The bird's endogenous secretions may aid fibre solubilization, facilitating not only $(a)$ its hydrolysis in the crop and hindgut by bacterial enzymic activity, but also $(b)$ hydrolysis by previously dormant enzymes intrinsic in the foodstuff and re-activated during passage through the digestive tract. While the former mechanism of fibre degradation would result in the production of volatile fatty acids, the latter might possibly provide a small amount of digestible sugars.

In the present study, pea hulls were chosen as an example of fibre from secondary cell walls, and carrot and cabbage fibre as examples of primary cell walls. All three feedingstuffs 
contained water-soluble pectic substances, while their negligible starch content eliminated any risk of inflating cellulose digestion through an inability to remove starch quantitatively from the input.

\section{MATERIALS AND METHODS \\ Feedingstuffs}

Dried peas, var. Progretta, were lightly hammered and the hulls manually separated from the cotyledons. The hulls were ground through a $1 \mathrm{~mm}$ sieve.

Fresh carrot and cabbage were finely chopped, frozen, freeze-dried and ground through a $1 \mathrm{~mm}$ sieve.

For analytical purposes samples were reground through a $0.12 \mathrm{~mm}$ sieve.

\section{Bioassay}

Individually caged adult cockerels, which had been starved for $48 \mathrm{~h}$ except for the administration of glucose, were tube-fed on each of the three feedingstuffs such that six birds received $50 \mathrm{~g}$ and six birds received $25 \mathrm{~g}$ (six birds $\times$ three feedingstuffs $\times$ two doses, i.e. thirty-six birds). The excreta (faeces + urine) voided during the subsequent $72 \mathrm{~h}$ were collected from trays placed under the cages, frozen at $-20^{\circ}$, freeze-dried, weighed and ground through a $1 \mathrm{~mm}$ sieve. A control group of six adult cockerels was given $50 \mathrm{~g}$ glucose and these birds provided a measurement of endogenous losses and contribution from bacteria to the excreta. Birds were given access to water and tube-fed on water twice during the $72 \mathrm{~h}$ collection period. Further details of the exact protocol followed is given elsewhere ( $\mathrm{McNab} \&$ Blair, 1988). Although the procedure has not previously been used except in this laboratory (Longstaff \& $\mathrm{McNab}, 1986,1987$ ) to measure the digestibility of the carbohydrate constituents of foods, it has been extensively applied to the determination of the digestibilities of the amino acids in dietary proteins where the same principles apply (Likuski \& Dorrell, 1978; Sibbald, 1986). Digestibility of fibre from pea hulls, carrot and cabbage was calculated for each bird. The fibre found in the excreta from the control birds given glucose was subtracted from that found in the excreta from birds given the experimental foods in order to determine true digestibility.

\section{Chemical analysis}

1. Colorimetric analysis of free sugars, 'sucrose' and starch. Reducing sugars were quantitatively measured colorimetrically using $p$-hydroxybenzoic acid hydrazide (PAHBAH) which reacts to form a yellow chromogen (Lever, 1972; Hudson \& John, 1976; Tawflik \& Mardon, 1985). Starch was converted to the reducing sugar glucose by the enzymic action of amyloglucosidase (EC 3.2.1.3, Sigma Chemical Co., Poole, Dorset) (Southgate, 1981; Theander \& Aman, 1981) and hydrolysis of sucrose to its reducing sugar components, glucose and fructose was achieved using the enzyme invertase $(E C$ 3.2.1.26, Sigma Chemical Co.) (Blakeney \& Mutton, 1980). The precise details of the procedure are as follows. Feedingstuffs $(50 \mathrm{mg})$ or excreta $(50 \mathrm{mg})$ were weighed into polypropylene tubes. $0.2 \mathrm{M}$-Sodium acetate buffer, $\mathrm{pH} 4.5(9 \mathrm{ml})$, was added and the capped tubes placed in an oven at $100^{\circ}$ for $4 \mathrm{~h}$ in order to gelatinize the starch. On cooling to below $50^{\circ}, 1 \mathrm{ml}$ sodium acetate buffer containing $0.1 \mathrm{mg}$ amyloglucosidase or $1 \mathrm{ml}$ buffer containing $0.1 \mathrm{mg}$ amyloglucosidase $+0.25 \mathrm{mg}$ invertase, or $1 \mathrm{ml}$ sodium acetate buffer (enzyme blank) was added and the contents of the tubes incubated at $50^{\circ}$ in a shaking water-bath for $16 \mathrm{~h}$. After cooling, $0.4 \mathrm{ml}$ supernatant fractions were diluted either to $100 \mathrm{ml}$ (feedingstuffs) or $20 \mathrm{ml}$ (excreta) and the free sugars, glucose from starch, and glucose + fructose ('sucrose') were measured colorimetrically after reaction with PAHBAH. The measurement of free sugars 
was obtained from the enzyme blank tube, starch by difference from tubes incubated with or without amyloglucosidase, and 'sucrose' by difference from tubes incubated with amyloglucosidase with or without invertase.

2. Analysis of free sugars and 'sucrose' by gas-liquid chromatography. Pea hulls, carrot and cabbage $(200 \mathrm{mg})$ were weighed into polypropylene tubes and destarched with or without the addition of invertase as described previously. An appropriate portion of supernatant fraction was evaporated to dryness and the monosaccharides present were converted to the corresponding alditol acetate and measured by gas-liquid chromatography according to the method of Blakeney et al. (1983).

3. Fibre preparation. The fractionation scheme employed here, whereby fibre polysaccharides were separated from starch and free sugars and collected as insoluble and total (soluble + insoluble) polysaccharides was essentially that recommended by Englyst et al. (1982) and Englyst \& Cummings (1984).

(a) Total polysaccharides (soluble + insoluble). To the feedingstuff and excreta solutions, prepared as described previously after the removal of $0.4 \mathrm{ml}$ supernatant fraction, were added $30 \mathrm{ml}$ absolute alcohol to make the final solution $75 \%$ with respect to alcohol. The tubes were left overnight at $4^{\circ}$ to aid precipitation of the water-soluble polysaccharides. Precipitates were washed three times with $30 \mathrm{ml} 80 \%$ ethanol to ensure removal of free sugars, 'sucrose' and glucose from starch and finally once with $30 \mathrm{ml}$ acetone. Precipitates were magnetically stirred when dry to a fine powder at $40^{\circ}$.

(b) Insoluble polysaccharides. To a parallel set of tubes containing destarched feedingstuffs and excreta, and after removal of $0.4 \mathrm{ml}$ supernatant fraction, were added 30 $\mathrm{ml} 0.2 \mathrm{M}$-sodium phosphate buffer, $\mathrm{pH} 7 \cdot 0$. The insoluble polysaccharides were washed three times with $30 \mathrm{ml}$ buffer to remove soluble polysaccharides, free sugars, 'sucrose' and glucose from starch and finally once with $30 \mathrm{ml}$ acetone. Insoluble fibre was magnetically stirred when dry to a fine powder at $40^{\circ}$.

4. Hydrolysis of fibre and derivatization of neutral sugars. (a) $12 \mathrm{M}$-sulphuric acid pretreatment followed by $1 \mathrm{M}-\mathrm{H}_{2} \mathrm{SO}_{4}$ hydrolysis. To the acetone-dried fibre from $50 \mathrm{mg}$ feedingstuffs or excreta was added $0.25 \mathrm{ml} 12 \mathrm{M}$-sulphuric acid and the tubes were whirled until the acid completely wetted the samples. The tubes were then placed in a water-bath at $40^{\circ}$ for $1 \mathrm{~h}$ with occasional whirling to aid solubilization. Volumes were diluted to $3 \mathrm{ml}$ $1 \mathrm{M}-\mathrm{H}_{2} \mathrm{SO}_{4}$ by the addition of $2.75 \mathrm{ml}$ of an aqueous solution of inositol $(2 \mathrm{mg} / \mathrm{ml})$. The tubes were then capped and heated for $3 \mathrm{~h}$ at $100^{\circ}$ in an oven.

(b) $1 \mathrm{M}-\mathrm{H}_{2} \mathrm{SO}_{4}$ hydrolysis of fibre. To the acetone-dried fibre from $50 \mathrm{mg}$ feedingstuffs or excreta were added $2.75 \mathrm{ml}$ of an aqueous solution of inositol $(2 \mathrm{mg} / \mathrm{ml})$, followed by $0.25 \mathrm{ml} 12 \mathrm{M}-\mathrm{H}_{2} \mathrm{SO}_{4}$; the capped tubes were placed in an oven at $100^{\circ}$ for $3 \mathrm{~h}$.

After hydrolysis solutions from $(a)$ and $(b)$ were neutralized with $15 \mathrm{M}$-ammonia and a $0.2 \mathrm{ml}$ portion taken for determination of alditol acetate formation by the method of Blakeney et al. (1983).

5. Measurement of uronic acids. Portions of hydrolysates from the feedingstuffs and excreta from 3(a) were diluted appropriately and analysed by the colorimetric method of Blumenkrantz \& Asboe-Hansen (1973). D-Galacturonic acid was used as a standard.

\section{RESULTS}

The free sugar, 'sucrose' and starch contents (the available carbohydrates) of pea hulls, carrot and cabbage measured colorimetrically are shown in Table 1 . The small quantity of starch detected in pea hulls probably arose from contamination of the hulls with cotyledon. Carrot and cabbage contained large amounts of free sugars but very little starch. Carrot contained the largest amount of 'sucrose'. The available carbohydrate contents of carrot 
Table 1. Free sugars, 'sucrose' and starch contents of pea (Pisum sativum) hulls, carrot and cabbage analysed colorimetrically ( $\mathrm{g} / \mathrm{kg}$ dry matter)

(Mean values and standard deviations)

\begin{tabular}{|c|c|c|c|c|c|c|c|c|}
\hline & \multicolumn{2}{|c|}{ Free sugars } & \multicolumn{2}{|c|}{ 'Sucrose' } & \multicolumn{2}{|c|}{ Starch } & \multicolumn{2}{|c|}{$\begin{array}{c}\text { Available } \\
\text { carbohydrate }\end{array}$} \\
\hline & Mean & $\mathrm{SD}$ & Mean & SD & Mean & SD & Mean & SD \\
\hline Pea hulls & $8 \cdot 35$ & 3.90 & $4 \cdot 86$ & 3.06 & $17 \cdot 74$ & $3 \cdot 23$ & $30 \cdot 95$ & $5 \cdot 63$ \\
\hline Carrot & 305.98 & $24 \cdot 30$ & $238 \cdot 98$ & 10.58 & $8 \cdot 47$ & 8.73 & 553.43 & $17 \cdot 77$ \\
\hline Cabbage & $485 \cdot 34$ & $33 \cdot 11$ & 63.88 & $6 \cdot 22$ & $21 \cdot 12$ & $24 \cdot 41$ & $570 \cdot 33$ & 19.46 \\
\hline
\end{tabular}

and cabbage were similar, 553.43 and $570.33 \mathrm{~g} / \mathrm{kg}$ respectively, comprising slightly more than half the dry matter content of these dicotyledons. In contrast, the available carbohydrate content of pea hulls was extremely low, $30.95 \mathrm{~g} / \mathrm{kg}$.

The monosaccharide compositions of the available carbohydrates of the three feedingstuffs are shown in Table 2 . With each feedingstuff fairly good agreement was found between values derived by the gas-liquid chromatographic method (Table 2) and those from the colorimetric method (Table 1). Because the gas-liquid chromatographic method was performed on samples that had been treated with amyloglucosidase, the free sugar component contained a small amount of glucose released from starch and, in the case of pea hulls, it is most likely that all this free glucose arose from contaminating starch. Although the alditol acetate of mannose was detected by gas-liquid chromatography, both in the free sugar and 'sucrose' components of carrot and cabbage, it is most unlikely that mannose occurred as a monosaccharide in its own right, but arose from the borohydride reduction of fructose (a keto-sugar) in the derivatization procedure. On reduction and acetylation, fructose gives equimolecular amounts of mannitol hexa-acetate and glucitol hexa-acetate. Therefore, from the free sugar component of carrot, it can be deduced that there was $157.19 \mathrm{~g}$ fructose $/ \mathrm{kg}(78.59 \mathrm{~g}$ mannitol hexa-acetate $/ \mathrm{kg}+78.59 \mathrm{~g}$ glucitol hexaacetate $/ \mathrm{kg}$ ) leaving only $105.56 \mathrm{~g}$ glucose $/ \mathrm{kg}$ present as a free sugar (184.15 $\mathrm{g}$ total glucitol hexa-acetate $/ \mathrm{kg}, 78.59 \mathrm{~g}$ glucitol hexa-acetate $/ \mathrm{kg}$ formed from fructose). Galactose occurred as a free sugar in carrot and cabbage, but not in pea hulls. By the same reasoning the fructose content of the 'sucrose' component of carrot can also be deduced. In this instance, however, fructose occurs, not as a monosaccharide but linked to glucose as half the 'sucrose' molecule before invertase treatment. Thus, carrot contained only $191.02 \mathrm{~g}$ true sucrose $/ \mathrm{kg}(95.51 \mathrm{~g}$ glucose $/ \mathrm{kg}+95.51 \mathrm{~g}$ fructose $/ \mathrm{kg})$ leaving $62.95 \mathrm{~g}$ fructose $/ \mathrm{kg}$ and $3.50 \mathrm{~g}$ galactose $/ \mathrm{kg}$ having arisen from some other source. Similar deductions were also made for pea hulls and cabbage.

The monosaccharide compositions of the hemicellulotic polysaccharides and the combined hemicellulotic and cellulotic polysaccharides are shown in Table 3 . In the case of the latter, analysis was extended to include insoluble as well as total (soluble + insoluble) polysaccharides. It can be seen that pea hulls contained the largest amount of hemicellulotic polysaccharides, composed mainly, although not exclusively, of xylose. Carrot and cabbage contained much less hemicellulose and only a very small amount of xylose-containing polysaccharides, typical of primary cell wall material. The mannose content of carrot and

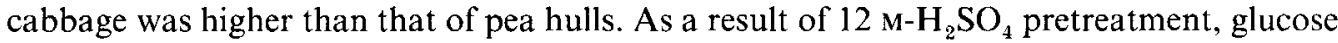
from cellulose contributed most to the increase in the sum of neutral sugars and to the greatest extent with pea hulls, typical of secondary cell wall material. The stronger acid 







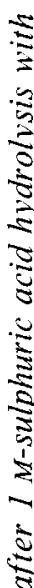

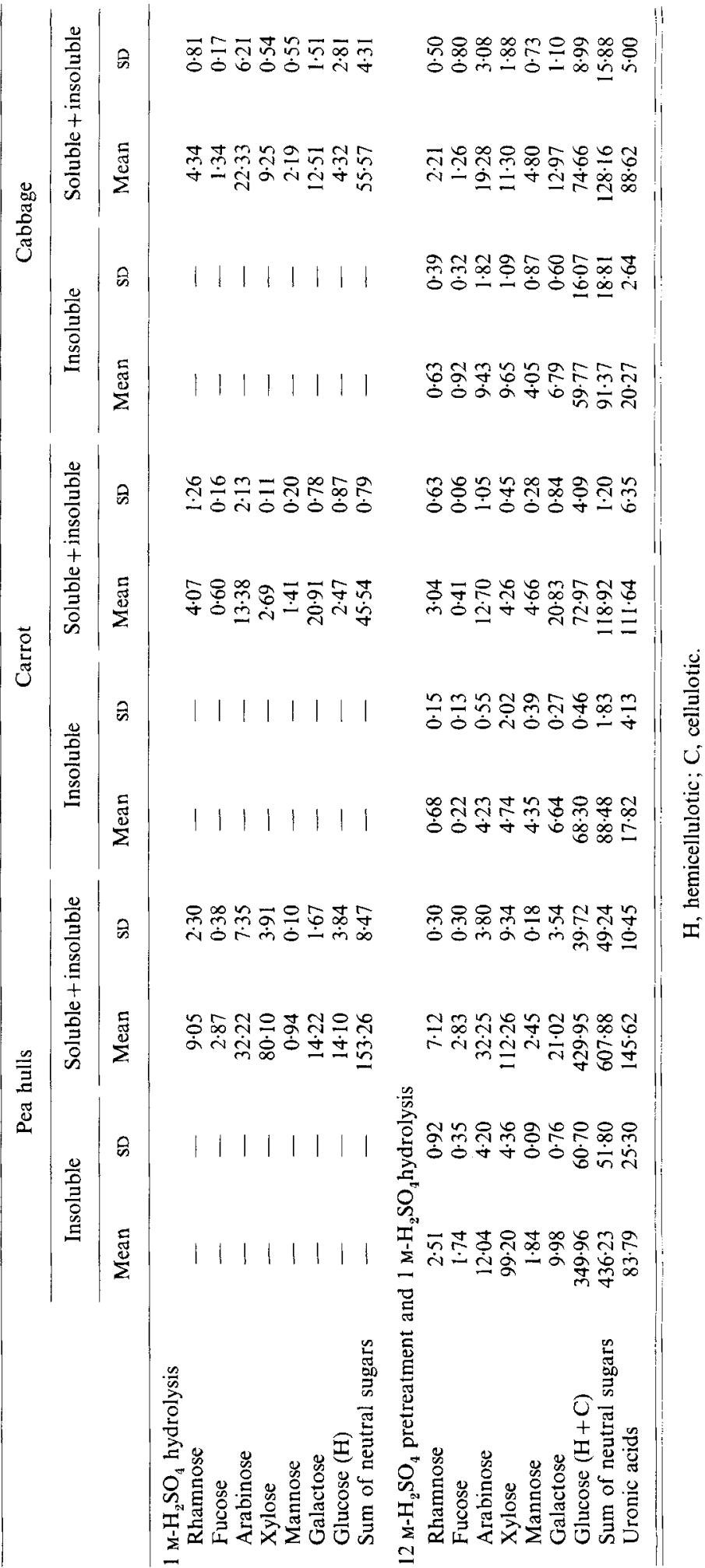


treatment increased the contributions from xylose and mannose, and decreased slightly those from rhamnose and arabinose, presumably because of their degradation. Although pea hulls contained the largest amount of acidic polysaccharides, measured as uronic acids, in proportion to their neutral polysaccharides the amount was small, whereas carrot and cabbage possessed almost equal amounts of neutral and acidic polysaccharides. Total (soluble + insoluble) polysaccharides and insoluble polysaccharides were measured directly, but soluble polysaccharides were derived by difference. It can be seen that polysaccharides containing fucose, xylose, mannose and glucose from cellulose were only sparingly soluble, while those containing rhamnose, arabinose and galactose, characteristic of pectic substances, were more readily soluble.

Because no significant differences in the digestibility of fibre were found between birds that had been fed on either $50 \mathrm{~g}$ or $25 \mathrm{~g}$ feedingstuffs the results were pooled to obtain twelve birds per feedingstuff. Digestibility of total (soluble + insoluble) hemicellulotic polysaccharides is shown in Table 4 . The overall digestibilities, calculated from the sum of neutral sugar residues, were very low, $6 \cdot 1,7 \cdot 0$ and $5.0 \%$ for pea hulls, carrot and cabbage respectively. The most digestible polysaccharides were those composed of rhamnose, arabinose, galactose and mannose. The extremely small amount of mannose-containing polysaccharide in pea hulls made accurate assessment of mannose in the excreta very difficult and, because more mannose was found in the excreta of control birds given glucose, all digestibilities were over $100 \%$. The least digestible polysaccharides were those consisting of fucose and xylose in all three feedingstuffs and those consisting of glucose from pea hulls and carrot. A hemicellulotic polysaccharide in cabbage containing glucose was quite well digested. Differences in digestibility of polysaccharides were found between the three feedingstuffs.

The digestibility of total hemicellulotic and cellulotic polysaccharide (soluble + insoluble) is shown in Table 5. The overall digestibilities, calculated from the sum of neutral sugars, were extremely low, on average $4 \cdot 2,0.8$ and $-3.6 \%$ for pea hulls, carrot and cabbage respectively. The decrease in digestibility after $12 \mathrm{M}-\mathrm{H}_{2} \mathrm{SO}_{4}$ pretreatment was a consequence of the greater contribution made by indigestible cellulose. The most digestible polysaccharides were those belonging to the pectic substances, composed of rhamnose, arabinose, galactose and galacturonic acid. The least digestible polysaccharides were those composed of fucose, xylose and glucose from cellulose. The uronic acid-containing polysaccharides of carrot and cabbage were much more digestible than those of pea hulls. Differences in polysaccharide digestibilities were found between the three feedingstuffs.

Table 6 shows the influence of sample weight on the quantification of total and insoluble acidic polysaccharides as measured by their uronic acid contents. It can be seen that a consistent recovery of total acidic polysaccharides in vitro was possible because of their complete precipitation after three washings with $30 \mathrm{ml}$ of $80 \%$ ethanol when sample weights of 50-200 mg feedingstuff (carrot) and 25-100 mg excreta (from two carrot-fed birds) were taken. On the other hand the quantity of insoluble acidic polysaccharides recovered after three washings with $30 \mathrm{ml}$ water increased with increasing sample weight both in feedingstuff and excreta. Hence acidic polysaccharide solubility decreased with increased sample weight: solvent ratio.

\section{DISCUSSION}

The amounts of free sugars and 'sucrose' measured by the colorimetric method using PAHBAH were in close agreement with those measured by gas-liquid chromatography. The latter method, however, revealed that the sucrose content had been overestimated, its value inflated by the presence of sugars most likely obtained from the invertase hydrolysis 


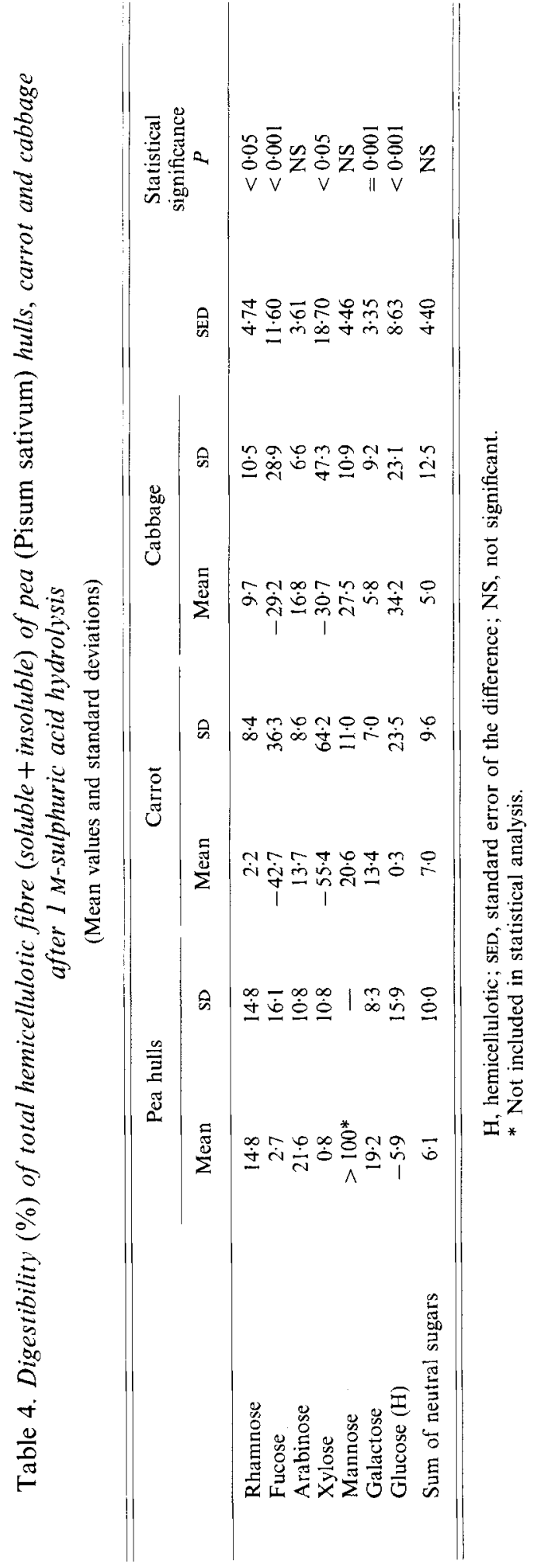







Table 6. Influence of sample concentration on the in vitro solubility of acidic polysaccharides

(Mean values and standard deviations)

\begin{tabular}{|c|c|c|c|c|c|c|}
\hline & & \multicolumn{2}{|c|}{$\begin{array}{l}\text { Total uronic acids } \\
(\mathrm{g} / \mathrm{kg} \mathrm{DM})\end{array}$} & \multicolumn{2}{|c|}{$\begin{array}{l}\text { Insoluble uronic } \\
\text { acids }(\mathrm{g} / \mathrm{kg} \text { DM })\end{array}$} & \multirow[b]{2}{*}{ Solubility } \\
\hline & & Mean & SD & Mean & $\mathrm{SD}$ & \\
\hline Carrot wt (mg): & $\begin{array}{r}50 \\
75 \\
100 \\
150 \\
200\end{array}$ & $\begin{array}{r}101.4 \\
99.4 \\
100 \cdot 3 \\
101.6 \\
89.4\end{array}$ & $\begin{array}{r}7 \cdot 1 \\
12 \cdot 0 \\
11 \cdot 4 \\
6 \cdot 2 \\
7 \cdot 8\end{array}$ & $\begin{array}{l}16 \cdot 6 \\
21 \cdot 7 \\
32 \cdot 3 \\
41 \cdot 9 \\
51 \cdot 4\end{array}$ & $\begin{array}{l}1 \cdot 9 \\
3 \cdot 3 \\
2 \cdot 2 \\
4 \cdot 7 \\
2 \cdot 3\end{array}$ & $\begin{array}{l}0.836 \\
0.782 \\
0.678 \\
0.587 \\
0.425\end{array}$ \\
\hline Excreta wt (mg): & $\begin{array}{r}25 \\
50 \\
75 \\
100\end{array}$ & $\begin{array}{l}152.0 \\
146.7 \\
151.5 \\
160.6\end{array}$ & $\begin{array}{l}22 \cdot 7 \\
24 \cdot 0 \\
10 \cdot 9 \\
19 \cdot 4\end{array}$ & $\begin{array}{r}54.3 \\
84.8 \\
101.9 \\
112.6\end{array}$ & $\begin{array}{r}7 \cdot 1 \\
20 \cdot 5 \\
7 \cdot 1 \\
6 \cdot 6\end{array}$ & $\begin{array}{l}0.643 \\
0.422 \\
0.327 \\
0.299\end{array}$ \\
\hline
\end{tabular}

DM, dry matter.

of galactosyl sucrose oligosaccharides. Invertase is known to hydrolyse the sucrose component of raffinose, stachyose and verbascose to release fructose, and any contaminating $\alpha$-galactosidase activity present in the invertase preparation may have hydrolysed the galactose linkages. Although it was expected that $80 \%$ ethanol would have achieved complete solubilization of these higher oligosaccharides, a small amount may have been precipitated along with the fibre fraction. If this was the case, then the fructose portion of the molecule may be the source of the readily digestible mannose observed after $1 \mathrm{M}-\mathrm{H}_{2} \mathrm{SO}_{4}$ treatment of the fibre. The mannose detected after $12 \mathrm{M}-\mathrm{H}_{2} \mathrm{SO}_{4}$ pretreatment is more likely to be a mannan polysaccharide closely associated with cellulose and, being more indigestible, would reduce the overall digestibility of mannose as seen with the stronger acid treatment.

Measurement of monosaccharides released after $1 \mathrm{M}-\mathrm{H}_{2} \mathrm{SO}_{4}$ hydrolysis shows that the digestion of total (soluble + insoluble) fibre by adult cockerels was very low, on average $6 \cdot 1$, 7.0 and $5.0 \%$ for pea hulls, carrot and cabbage respectively. After $12 \mathrm{M}-\mathrm{H}_{2} \mathrm{SO}_{4}$ pretreatment to solubilize cellulose, digestion of fibre was even lower, on average $4 \cdot 2,0.8$ and $-3.6 \%$ for pea hulls, carrot and cabbage respectively, because of the increased proportion of indigestible cellulose present. However, digestion expressed as the sum of neutral sugars concealed the greater digestibility of the pectic polysaccharides which were the source of rhamnose, arabinose, galactose and galacturonic acid to the hydrolysis medium. These pectic polysaccharides (rhamnogalacturonans, arabinans and galactans) were digested to a greater extent in all three feedingstuffs (on average from both types of hydrolysis 11.9, 15.2 and $12.9 \%$ respectively) than polysaccharides composed of fucose, xylose and glucose from cellulose. This greater digestion of pectic polysaccharides in dicotyledons compared with xylans and cellulose is in agreement with findings from other simple stomached animals (Graham et al. 1986; Longstaff \& McNab, 1986), ruminant studies (Dekker et al. 1972; Chesson \& Monro, 1982; Ben-Ghedalia \& Miron, 1984) and in vitro studies using rumen fluid (Åman \& Nordkvist, 1983; Nordkvist \& Åman, 1986).

Polysaccharides containing uronic acids from pea hulls were only digested to a small extent $(5.3 \%)$ in contrast to their greater digestibility in carrots $(24.2 \%)$ and cabbage $(27.5 \%)$. Unfortunately there is no suitable simple colorimetric method available which will 
distinguish between glucuronic acid, associated with acidic xylans, and galacturonic acid, a constituent of pectic polysaccharides. Although pea hulls are known to contain pectic substances, they are also rich in acidic xylans and cellulose (Selvendren, 1985). BenGhedalia \& Miron (1984) showed that the uronic acid associated with the insoluble cell wall material of lucerne (Medicago sativa) (glucuronic acid) was digested by sheep to the extent of $40 \%$, whereas the soluble uronic acid (galacturonic acid) from pectic substances was digested $86.5 \%$.

The large negative digestibility coefficients obtained for fucose and xylose are difficult to explain. Negative xylose digestibilities have occurred in findings from other studies with sugar-beet pulp, but not with wheat bran (Graham et al. 1986) and negative xylose, fucose and glucose digestibilities have occurred after guar gum ingestion by human volunteers (Nyman et al. 1986). Negative rhamnose, fucose, xylose, mannose and glucose digestibilities were found after giving a basal diet containing insoluble lupin-seed polysaccharides as well as after giving the low-fibre basal diet itself to adult cockerels (Carre \& Leclercq, 1985). After correction for polysaccharide excretion from birds fed on the basal diet, these latter authors found that negative digestibilities only remained in the case of xylose and only to a small extent. Negative digestibility coefficients for xylose were not observed after arabinoxylan ingestion from wheat (Longstaff \& $\mathrm{McNab}, 1986$ ) nor in the present study with pea hulls. This could arise because the fucose and xylose contents of pea hulls and the xylose content of wheat are much higher than those in carrot and cabbage and so digestibilities are less affected by endogenous, bacterial or previous dietary residues containing these constituents. Microscopic examination of excreta from birds given carrot and cabbage revealed the presence of aleurone cell walls, which undoubtedly arose from food consumed before the start of the balance experiment, and aleurone cell walls were also detected in excreta from control birds fed on glucose. Carrot and cabbage may also encourage more bacterial proliferation (Eastwood, 1985) or induce excretion of more endogenous material for which control birds cannot properly compensate. The excess fucose-polysaccharide material appeared to be mainly soluble. Fucose-containing polysaccharides from dietary fibre were only sparingly soluble and it seems likely that the fucose in excreta had arisen from endogenous material.

An interesting aspect of the present work was the solubility characteristics of polysaccharides, and one of the questions to be answered appears to be whether or not water-soluble polysaccharides are more digestible than insoluble polysaccharides by simple-stomached animals. Soluble polysaccharides such as pectins are believed to be readily fermented in man and pigs (Graham et al. 1986; Nyman et al. 1986; Longland \& Low, 1988). When sugar beet was fed to pigs, Graham et al. (1986) found an increased concentration of soluble polysaccharides in the ilea of the pigs compared with that found in the feedingstuff, and this suggested to them that pectins were being solubilized during passage down the digestive tract. This could explain the apparently large negative digestibility coefficient observed for soluble polysaccharides with ileal digesta samples. They also reported a subsequent decrease in the concentration of soluble polysaccharides in the excreta and implied that the disappearance was caused by fermentation. They did not, however, give precise details of the method used to quantify both soluble and total polysaccharides, such as weights of feedingstuff, digesta and excreta samples taken, nor the amount of solvent used for extraction. The present study also suggests that the most readily digested polysaccharides appear to be the most soluble. The difficulty lies, however, in quantifying soluble polysaccharides. While it may be reasonable to conclude that some polysaccharides such as cellulose and acidic xylans may remain sparingly soluble in any amount of solvent, the solubility of others appears to be arbitrary, and it is this very arbitrariness which makes a quantitative investigation into their digestibility exceedingly difficult. 
It was the initial intention in the present study to investigate the digestibilities of insoluble (measured) and soluble (by difference from total) polysaccharides separately, but results have not been reported as subsequent findings (Table 6) of the influence of sample weight and, hence, fibre concentration on solubility, made sensible conclusions difficult. To illustrate this point, the results of digestibilities with carrot are given now. Total and insoluble fibres were prepared in the same manner from $50 \mathrm{mg}$ of feedingstuff and $50 \mathrm{mg}$ excreta (from twelve birds), and uronic acids measured. The amounts of soluble uronic acid ingested by birds fed on 50 or $25 \mathrm{~g}$ carrot were 4388 and $2193 \mathrm{mg}$ respectively, and the average amounts excreted by the two groups of six birds were $1985 \mathrm{mg}$ and $1204 \mathrm{mg}$ respectively, giving an overall average digestibility of $49.9 \%$. Similarly, the amounts of insoluble uronic acids ingested by birds fed on 50 or $25 \mathrm{~g}$ carrot were $833 \mathrm{mg}$ and $416 \mathrm{mg}$ respectively and the amounts excreted were $1878 \mathrm{mg}$ and $821 \mathrm{mg}$ respectively, giving a large negative digestibility of $-111.4 \%$ overall. Cabbage values gave similar results. This might have led to the conclusion that pectins previously soluble in the feedingstuff were being precipitated in the gut. However, birds fed on pea hulls did not show this apparent increase in insoluble acid polysaccharides in excreta. These findings have most likely arisen because the concentration of fibre in the excreta from birds fed on carrot and cabbage was much greater than that in the feedingstuff, whereas the fibre concentration in excreta from birds fed on pea hulls was much closer to that in the feedingstuff. It is not possible to calculate in advance this fibre difference and so weigh out feedingstuff and excreta samples of equivalent fibre content, since it necessitates an a priori knowledge of its concentration in excreta, which is the precise issue under examination.

In conclusion, the small amount of fibre digestion found in the present study with adult cockerels is in contrast to the large amounts which are purported to be digested by the pig, rat and man. This difference may be partly due to the stringent control of fibre intake and quantitative collection of output with this bioassay. Such feeding protocols have rarely been used with other species. On the other hand, poultry may lack an extensive bacterial population in their hindgut and, together with the shorter residence time, this may limit the extent of fermentation. Nevertheless, a similarity between chickens and other species has been demonstrated, in that they appear preferentially to digest water-soluble pectic substances.

The authors express their sincere thanks to Anne Knox for expert assistance in chemical analysis and to Kim Henderson for thorough skill in tube feeding and excreta collection.

\section{REFERENCES}

Åman, P. \& Nordkvist, E. (1983). Chemical composition and in vitro degradability of major chemical constituents of red clover harvested at different stages of maturity. Journal of the Science of Food and Agriculiure 34, $1185-1189$.

Asp, N. \& Johansson, C. (1981). Techniques for measuring dietary fibre; principal aims of methods and a comparison of results obtained by different techniques. In The Analysis of Dietary Fibre in Food, pp. 173-189 [W. P. T. James and O. Theander, editors). New York: Marcel Dekker.

Bach Knudsen, K. E., Agergaard, N. \& Olesen, H. P. (1985). Influence of caecectomy on transit time and digestibility of non-starch polysaccharides (NSP) in rats. In Proceedings of the XIII International Congress of Nutrition, Brighton, Abstr., p. 67.

Ben-Ghedalia, D. \& Miron, J. (1984). The digestion of total and cell wall monosaccharides of alfalfa by sheep. Journal of Nutrition 114, 880-887.

Blakeney, A. B., Harris, P. J., Henry, R. J. \& Stone, B. A. (1983). A simple and rapid preparation of alditol acetates for monosaccharide analysis. Carbo'tydrate Research 113, 291-299.

Blakeney, A. B. \& Mutton, L. L. (1980). A simple colorimetric method for the determination of sugars in fruit and vegetables. Journal of the Science of Food and Agriculture 31, 889-897.

Blumenkrantz, N. \& Asboe-Hansen, G. (1973). A new method for quantitative determination of uronic acids Analytical Biochemistry 54, $484-489$. 
Bolton, W. (1954). The digestibility of the carbohydrate complex of bran and rats by adult cocks. Worlds Poultry Congress 28, 94-98.

Bolton, W. (1955). The digestibility of the carbohydrate complex of barley, wheat and maize by adult fowls. Journal of Agricultural Science, Cambridge 46, 119-122.

Bylund, M. \& Donetzhuber, A. (1968). A semi-micro determination of uronic acids. Svensk Papperstidning 15. $505-508$

Carre, B. \& Leclercq, B. (1985). Digestion of polysaccharides, protein and lipids by adult cockerels fed on diets containing a pectic cell-wall material from white lupin (Lupinus albus L.) cotyledon. British Journal of Nutrition 54, 669-680.

Cerda, J. J., Robins, F. L. \& Burgin, C. W. (1985). The effectiveness of grapefruit pectin in lowering plasma cholesterol in miniature swine. In Proceedings of the XIII International Congress of Nutrition, Brighton, Abstr., p. 68.

Chen, W. J. L., Anderson, J. W. \& Jennings, D. (1984). Propionate may mediate the hypocholesterolemic effects of certain soluble plant fibres in cholesterol fed rats. Proceedings of the Society of Experimental Biology and Medicine 175, 215-218.

Chesson, A. \& Monro, J. A. (1982). Legume pectic substances and their degradation in the ovine rumen. Journal of the Science of Food and Agriculture 33, 852-859.

Dekker, R. F. H., Richards, G. N. \& Playne, M. J. (1972). Digestion of polysaccharide constituents of tropical pasture herbage in the bovine rumen. Carbohydrate Research 22, 173-185.

Eastwood, M. A. (1985). An examination of factors which may affect the water-holding capacity of dietary fibre. In Proceedings of the XIII International Congress of Nutrition, Brighton, pp. 181-183 [T. G. Taylor and N. K. Jenkins, editors]. London: John Libbey.

Eastwood, M. A. \& Robertson, J. A. (1978). The place of dietary fibre in our diet. Journal of Human Nutrition 32, 53-61.

Englyst, H. N. \& Cummings, J.H. (1984). Simplified method for the measurement of total non-starch polysaccharides by gas-liquid chromatography of constituent sugars as alditol acetates. Analyst 109, 937-942.

Englyst, H., Wiggins, H. S. \& Cummings, J. H. (1982). Determination of the non-starch polysaccharides in plant foods by gas--liquid chromatography of constituent sugars as alditol acetates. Analyst 107, 307 318.

Goering, H. K. \& Van Soest, P. J. (1970). Forage fibre analysis. Agricultural Handbook no. 379. Washington DC: USDA.

Gohl, B. \& Gohl, I. (1977). The effect of viscous substances on the transit time of barley digesta in rats. Journal of the Science of Food and Agriculture 28, $911-915$.

Graham, H., Åman, P., Newman, R. K. \& Newman, C. W. (1985). Use of a nylon-bag technique for pig feed digestibility studies. British Joumal of Nutrition 54, 719-726.

Graham, H., Hesselman, K. \& Åman, P. (1986). The influence of wheat bran and sugar-beet pulp on the digestibility of dietary components in a cereal-based pig diet. Journal of Nutrition 116, 242-251

Hudson, G. \& John, M. V. (1976). The automated determination of carbohydrate. Journal of the Science of Food and Agriculture 27, 681-687.

Jenkins, D. J. A., Leeds, A. R., Gassuel, M. A., Goff, D. V., Wolever, T. M. S. \& Alberta, K. G. M. M. (1977). Viscosity and action of unavailable carbohydrate in reducing the post prandial glucose and insulin levels. Proceedings of the Nutrition Society 36, 46A.

Johnson, I. T. \& Gee, J. M. (1986). Gastrointestinal adaptation in response to soluble non-available polysaccharides in the rat. British Journal of Nutrition $\mathbf{5 5}, 497-505$.

Lever, M. (1972). A new reaction for colorimetric determination of carbohydrates. Analytical Biochemistry 47. $273-279$.

Likuski, H. J. A. \& Dorrell, H. G. (1978). A bioassay for rapid determination of amino acid availability values. Poultry Science 57, 16581660.

Longland, A. C. \& Low, A. G. (1988). The digestion of three sources of dietary fibre by growing pigs. Proceedings of the Nutrition Society 47, 104A.

Longstaff, M. \& McNab, J. M. (1986). Influence of site and variety on starch, hemicellulose and cellulose composition of wheats and their digestibilities by adult cockerels. British Poultry Science 27, 435.449.

Longstaff, M. \& McNab, J. M. (1987). Digestion of starch and fibre carbohydrates in peas by adult cockerels. British Poultry Science 28, 261-285.

Low, A. G. \& Rainbird, A. L. (1984). Effect of guar gum on nitrogen secretion into isolated loops of jejunum in conscious growing pigs. British Journal of Nutrition 52, 499-505.

McNab, J. M. \& Blair, J. C. (1988). Modified assay for true and apparent metabolisable energy based on tube feeding. British Poultry Science 29, 697-707.

Mathe, D., Lutton, C., Routurean, J., Coste, T., Goufficr, E., Sulpice, J. C. \& Chevallier, F. (1977). Effects of dietary fibre and salt mixtures on the cholesterol metabolism of rats. Journal of Nutrition, 107, 466-474.

Meittinen, T. A. \& Tarpila, S. (1977). Effect of pectin on serum cholesterol, faecal bile acids and biliary lipids in normolipidemic and hyperlipidemic individuals. Clinica Chimica Acta 79, 471-477.

Millard, P. \& Chesson, A. (1984). Modification to swede (Brassica napus L.) anterior to the terminal ileum of pigs: some implications for the analysis of dietary fibre. British Journal of Nutrition 52, 583-594. 
Nordkvist, E. \& Aman, P. (1986). Changes during growth in anatomical and chemical composition and in vitro degradability of lucerne. Journal of the Science of Food and Agriculture 37, 1-7.

Nyman, M., Asp. N.-G., Cummings, J. \& Wiggins, H. (1986). Fermentation of dietary fibre in the intestinal tract: comparison between man and rat. British Journal of Nutrition 55, 487-496.

Robertson, J. A., Eastwood, M. A. \& Yeoman, M. M. (1980). Bile salt adsorption ability of dietary fibre from named varieties of carrot at different developmental ages. Journal of Nutrition 110, 1130-1137.

Selvendren, R. R. (1985). The chemistry of dietary fibre. In Proceedings of the XIII International Congress of Nutrition, Brighton, pp. 163-167 [T. G. Taylor and N. K. Jenkins, editors]. London: John Libbey.

Sibbald, I. R. (1986). The TME System of Feed Evaluation: Methodology, Feed Composition Data and Bibliography. Ottawa: Research branch, Agriculture Canada.

Southgate, D. A. T. (1981). Use of the Southgate method for unavailable carbohydrates in the measurement of dietary fibre. In The Analysis of Dietary Fibre in Food, pp. 1-19 [W. P. T. James and O. Theander, editors]. New York: Marcel Dekker.

Stanogias, G. \& Pearce, G. R. (1985). The digestion of fibre by pigs. 1. The effects of amount and type of fibre on apparent digestibility, nitrogen balance and rate of passage. British Journal of Nutrition 53, 513-530.

Stephen, A. M. \& Cummings, J. H. (1980). Mechanism of action of dietary fibre in the human colon. Nature 284, $283-284$

Tawflik, A. M. \& Mardon, C. J. (1985). Automated analytical method for the determination of individual sugars in mixtures of glucose, fructose and sucrose. Journal of the Science of Food and Agriculture 36, 621-627.

Theander, O. \& Aman, P. (1979). Studies on dietary fibres. 1. Analysis and chemical characterisation of watersoluble and water-insoluble dietary fibres. Swedish Journal of Agricultural Research 9, 99-106.

Theander, O. \& Åman, P. (1981). Analysis of dietary fibres and their main constituents. In The Analysis of Dietary Fibre in Food, pp. 51-70 [W. P. T. James and O. Theander, editors]. New York: Marcel Dekker.

Tsai, A. C. \& Peng, B. (1981). Effects of locust bean gum on glucose tolerance, sugar digestion and gastric motility in rats. Journal of Nutrition 111, 2152-2156.

Williams, R. D. \& Olmsted, W. H. (1925). A biochemical method for determining indigestible residue (crude fibre) in faeces, lignin, cellulose and non-water-soluble hemicelluloses. Journal of Biological Chemistry 108, 653-666. 